\title{
Coordinating thoughts on coordination failures
}

Citation for published version (APA):

Herings, P. J. J. (2001). Coordinating thoughts on coordination failures. METEOR, Maastricht University School of Business and Economics. METEOR Research Memorandum No. 030

https://doi.org/10.26481/umamet.2001030

Document status and date:

Published: 01/01/2001

DOI:

10.26481/umamet.2001030

Document Version:

Publisher's PDF, also known as Version of record

\section{Please check the document version of this publication:}

- A submitted manuscript is the version of the article upon submission and before peer-review. There can be important differences between the submitted version and the official published version of record.

People interested in the research are advised to contact the author for the final version of the publication, or visit the DOI to the publisher's website.

- The final author version and the galley proof are versions of the publication after peer review.

- The final published version features the final layout of the paper including the volume, issue and page numbers.

Link to publication

\footnotetext{
General rights rights.

- You may freely distribute the URL identifying the publication in the public portal. please follow below link for the End User Agreement:

www.umlib.nl/taverne-license

Take down policy

If you believe that this document breaches copyright please contact us at:

repository@maastrichtuniversity.nl

providing details and we will investigate your claim.
}

Copyright and moral rights for the publications made accessible in the public portal are retained by the authors and/or other copyright owners and it is a condition of accessing publications that users recognise and abide by the legal requirements associated with these

- Users may download and print one copy of any publication from the public portal for the purpose of private study or research.

- You may not further distribute the material or use it for any profit-making activity or commercial gain

If the publication is distributed under the terms of Article $25 \mathrm{fa}$ of the Dutch Copyright Act, indicated by the "Taverne" license above, 


\title{
Coordinating Thoughts on Coordination Failures
}

\author{
P. Jean-Jacques Herings` \\ Department of Economics, Universiteit Maastricht, P.O. Box 616, 6200 MD \\ Maastricht, The Netherlands. Homepage: http://www.fdewb.unimaas.nl/algec/ \\ E-mail: P.Herings@algec.unimaas.nl
}

\begin{abstract}
Coordination failures constitute an alternative explanation for underemployment that complements the Keynesian and neo-classical views. The paper proposes to distinguish three classes of models with coordination failures. The classes are formed by strategic models with or without a coordinating role for prices, and general equilibrium models. The main insights resulting for each class of models are exhibited. It is argued that coordination failures are likely to arise in a decentralized economy, even under conditions where perfect competition could prevail. The paper concludes by pointing out several promising directions for future research.
\end{abstract}

\section{Introduction}

There are two quite distinct views when studying the underemployment of resources. One view is the neo-classical view. Underemployment of resources may occur, but is either a voluntary choice, or a temporary phenomenon that results from unimportant frictions in the process of matching supply and demand. This view is expressed by the well-known quote from Friedman (1968)

At any moment in time there is some level of employment which has the property that it is consistent with equilibrium in the structure of real wage rates ... The 'natural rate of unemployment', in other words, is the level that would be ground out by the Walrasian system of general equilibrium equations, provided that there is embedded in them the actual structural characteristics of the labor and commodity markets.

The Keynesian tradition on the contrary stresses non-rational expectations and wage and price rigidities in its explanation of underemployment of resources. This lead has been followed in theories on temporary equilibrium, see Grandmont (1987) for a survey, and in the fix-price literature, originating from the work of Bénassy (1975), Drèze (1975), and Younès (1975). The fixprice literature allows for a consistent modeling of the consequences of trade

\footnotetext{
* I would like to thank Joan Muysken, Erik de Regt and an anonymous referee for helpful comments to an earlier draft of this paper.
} 
at non-Walrasian prices, including the modeling of spill-over effects to other markets caused by price rigidities in one market.

The typical argument made against the fix-price literature is that it fails to explain why prices are rigid, and in particular why prices might deviate from Walrasian values for prolonged periods of time. Within the general equilibrium paradigm, there are at least three possible responses to this question. Blad (1978) stresses that price adjustment processes need not converge to an equilibrium, and that convergence, even if it takes place, can take quite some time. This view is reinforced in Weddepohl (1997), where it is shown that a discrete time tâtonnement process can generate periodic and chaotic paths. Secondly, Herings (1997) and Tuinstra (2000) show that political interference in the market mechanism can be rational from a partisan point of view and might be responsible for sustained deviations from prices that clear markets. Thirdly, Drèze and Gollier (1993) and Drèze (2001) argue that price rigidities are a response to market incompleteness. This argument is particularly valid for the two forms of underemployment most frequently encountered, unemployed labor and excess capacities. These are two clear examples of commodities for which future markets are hardly developed.

Notwithstanding the importance of the models in the fix-price tradition, it is by no means clear that they encompass all that can be said about underemployment of resources. One is lead to wonder whether underemployment of resources is impossible when expectations are rational and prices attain Walrasian values, a conclusion that seems to emerge from the neo-classical literature. Any underemployment resulting under these ideal circumstances is said to be caused by coordination failures.

This paper identifies three classes of models with coordination failures. The first class consists of rather abstract game-theoretic models, following the seminal work of Bryant (1983). This part of the literature makes it very clear that coordination failures are perfectly consistent with rational expectations. They lack, however, a coordinating role for the price mechanism. Strategic models with a coordinating role for prices constitute the second class. It is argued that outcomes in strategic models are often not robust to slightly different specifications of the model. Moreover, strategic models usually only permit a partial analysis, and this only under very specific assumptions with respect to the economic primitives. The third class of models consists of general equilibrium models of coordination failures. This class extends a partial analysis to a global one, and leads to results that are quite general. Section 2 lists the contributions of the game-theoretic literature on coordination failures. The following three sections discuss the three model classes. The final section concludes and highlights some issues that figure prominently on the research agenda. 


\section{Coordination Games}

The analysis of economies where Walrasian prices prevail and where agents make rational decisions has been the centerpiece of economics for a long time. In this setting, the Walrasian allocation is within reach, and, in the absence of externalities, is known to be Pareto optimal. This is the central message of the first welfare theorem. It is clear that any underutilization of a valuable resource, that is a resource with a positive price, is bound to lead to inefficiencies. Underutilization of resources is not even second best in this case. If trade takes place at Walrasian prices, and all agents behave rationally, then moving to the Walrasian allocation leads to a Pareto improvement. This suggests the following as a general definition of a coordination failure: If society fails to reach an outcome that is feasible and that everyone prefers, then the members of society have failed to coordinate in some way.

A mere inspection of the definition of a coordination failure may suggest a coordination failure is far-fetched. If a feasible Pareto improving outcome exists, it seems that rational agents should be able to enforce it in one way or another. A simple game-theoretic insight reveals that this is not the case. Consider the normal form game with two players depicted in Figure 1. This

\begin{tabular}{l|ll|ll|} 
& \multicolumn{2}{|c|}{$\mathrm{L}$} & \multicolumn{2}{|c|}{$\mathrm{R}$} \\
\hline $\mathrm{T}$ & 1 & & 0 & \\
& & & & \\
\hline $\mathrm{B}$ & 0 & & 2 & \\
& & 0 & & 2 \\
\hline
\end{tabular}

Fig. 1. A pure coordination game

game has two Nash equilibria in pure strategies, $(T, L)$ and $(B, R)$. Moreover, there is one equilibrium in mixed strategies, where the actions $\mathrm{T}$ and $\mathrm{L}$ are chosen with probability $2 / 3$ by agents 1 and 2 , respectively. Despite the extensive literature on refinements of Nash equilibrium, none of the existing equilibrium refinements can exclude any of the three Nash equilibria as being nonsensible. It is clear that the Nash equilibrium $(T, L)$ suffers from severe coordination failures.

It is obvious that a far majority of players will be able to coordinate on $(\mathrm{B}, \mathrm{R})$, which has been confirmed in experiments. Moreover, a number of more sophisticated approaches in the literature that attempt to model communication, also reach the conclusion that $(\mathrm{B}, \mathrm{R})$ should be played by rational players. Kalai and Samet (1985) show that a multistage unanimity game where non-cooperative players end up at an equilibrium which is symmetric and persistent leads to the play of $(\mathrm{B}, \mathrm{R})$. Herings, Mauleon and 
Vannetelbosch (2001) show that the possibility to make a commitment not to play certain strategies combined with the use of a mediator that produces an arbitrary match within the remaining strategies when possible, leads to the play of $(B, R)$.

A more serious challenge is posed by the stag hunt game depicted in Figure 2 that is taken from Aumann (1990). A player has the choice to hunt

\begin{tabular}{l|ll|ll|} 
& \multicolumn{2}{|c|}{$\mathrm{R}$} & \multicolumn{2}{|c}{$\mathrm{D}$} \\
\hline $\mathrm{R}$ & 7 & & 8 & \\
& & 7 & & 0 \\
\hline $\mathrm{D}$ & 0 & & 9 & \\
& & & & \\
& & 8 & & 9 \\
\hline
\end{tabular}

Fig. 2. The stag hunt game

rabbit or deer. A player can hunt rabbits by himself, and get a guaranteed payoff of at least 7 . To hunt deer, the collaboration of others is needed. The potential payoffs of hunting deer are equal to 9 , but are also quite risky. It is only if the other player also chooses to hunt deer that these payoffs are collected. Otherwise the player is left with payoffs equal to 0 .

The most frequently applied game-theoretic solution concept, the one of pure strategy Nash equilibrium, specifies two possible solutions. Either both players hunt rabbits, or both players hunt deer. Both players have payoffs equal to 7 in the former equilibrium, versus payoffs of 9 in the latter. None of the existing equilibrium refinements rules out one of the two equilibria. Notice that communication will not be of great help in this game. Both players would like to invoke the other one to choose $\mathrm{D}$, and will announce to do so themselves. But when actually making their decision, they might well choose the safe strategy R. Contrary to the game in Figure 1, experiments reveal a frequent occurrence of the Pareto dominated outcome $(R, R)$.

In fact, it is possible to make a case for the play of $(R, R)$ on at least three different accounts. Harsanyi and Selten (1988) argue that the solution to a game should not change if one adds a constant to the payoff of a player, where the constant depends only on the strategy chosen by the player's opponent. The reason is that addition of such a constant does not change the best response correspondence of the game. Adding the constant -8 to the payoff of a player when the opponent chooses D, shows that the game of Figure 2 is equivalent to the one depicted in Figure 3.

Any argument that was used to motivate the lower-right cell as the most sensible outcome in the game of Figure 1, can now be used to argue that the Pareto dominated outcome $(\mathrm{R}, \mathrm{R})$ results in the game of Figure 3 . This equilibrium is called the risk dominant equilibrium by Harsanyi and Selten 


\begin{tabular}{l|ll|ll|} 
& \multicolumn{2}{|c|}{$\mathrm{R}$} & \multicolumn{2}{|c}{$\mathrm{D}$} \\
\hline $\mathrm{R}$ & \multicolumn{1}{|c|}{7} & & 0 & \\
& & 7 & & 0 \\
\hline $\mathrm{D}$ & 0 & & 1 & \\
& & & & \\
\hline
\end{tabular}

Fig. 3. Transformation of the stag hunt game

(1988). For general symmetric $2 \times 2$ games with two strict Nash equilibria, the risk dominant Nash equilibrium is the one that consists of the strategies players would choose if they believe each of the actions of the opponents to be played with equal probability. A risk dominant Nash equilibrium need not be Pareto optimal.

A second argument for the play of the risk dominant Nash equilibrium comes from Carlsson and van Damme (1993). They show how a small amount of uncertainty about the coordination game that is actually played, forces players to take a global perspective, in which they can reason themselves to the play of the risk dominant equilibrium.

Finally, Ellison (1993), Kandori, Mailath, and Rob (1993) and Young (1993) take the perspective of repeated play of a coordination game by myopic players. Players choose in each period the action that performed best in the previous period, but do so subject to mistakes. They show that the resulting dynamic system is most frequently in the state where all players choose the risk dominant action.

\section{Strategic Models of Coordination Failures}

Bryant (1983) provides an economic model with coordination failures. Consider an economy consisting of $n N$ individuals. The individuals are located at $N \geq 2$ separate sites with $n$ individuals at each site. Each site produces an intermediate good, that is transformed into a final output by means of a Leontiev technology. The amounts $I_{1}, \ldots, I_{N}$ of intermediate goods are transformed into $N \min \left\{I_{1}, \ldots, I_{N}\right\}$ units of the final output. The intermediate goods are produced from leisure on a one for one basis. Individuals care about leisure and the consumption of the final output. For simplicity it is assumed that the final output is divided equally among all individuals.

The crux of the model is that each site decides independently from the other sites how much of the intermediary good to produce. This captures the essence of the specialized, multi-staged and decentralized production that characterizes an advanced economy. When a site has to determine the amount of intermediary good to be produced, it is not informed about the amounts 
produced at the other sites. It is therefore important that there are at least two sites.

Bryant's model admits a straightforward competitive analysis. The constant returns to scale production process fixes the real wage to be equal to one. The first order conditions for utility maximization then require that each household supplies an amount $\bar{I}$ of leisure in return for $\bar{I}$ units of the final output, where $\bar{I}$ is such that the marginal rate of substitution of leisure for consumption equals one.

Bryant's model as formalized above is simply a normal-form game, which is analyzed by considering its Nash equilibria. One possible Nash equilibrium coincides with the competitive solution. Given that all other individuals put in $\bar{I}$ units of leisure, it is optimal for an agent to supply $\bar{I}$ units of leisure himself. Supplying more than $\bar{I}$ units does not lead to more consumption because of the Leontiev technology, but is costly as it provides less leisure. Supplying less than $\bar{I}$ units leads to less consumption and more leisure, but involves a utility loss if the utility function is strictly quasi-concave.

Surprisingly, the reasoning above remains true for any effort level $I$ less than $\bar{I}$. If all other individuals put in $I<\bar{I}$ units of leisure, an agent does not want to supply less than $I$ units himself, since the marginal rate of substitution of leisure for consumption is more than one at effort level $I<\bar{I}$. An agent does not want to supply more than $I$ units, since that does not lead to more consumption because of the Leontiev technology. The strategy tuples where all individuals supply $I \leq \bar{I}$ units of labor characterize the set of symmetric Nash equilibria. There is a continuum of equilibria, ranging from a no-trade equilibrium to a competitive equilibrium. Almost all equilibria display coordination failures. Even though the competitive equilibrium is an outcome, the arguments of Section 2 imply that it is not obvious that agents are able to coordinate on it.

Indeed, the structure of Bryant's game is similar to the one of the stag hunt game. Suppose that there are only two sites, there is only one individual per site and individuals have only two effort levels; either an individual remains inactive or an individual provides the competitive effort level. In the former case, the individual knows for sure that there will be no consumption of the final output. In the latter case, there will only be consumption of the final output if the other individual provides the competitive effort level, otherwise the individual will not consume any final output, while still making all the effort. It might well be that remaining inactive corresponds to the risk dominant Nash equilibrium.

Bryant's model has been generalized in Cooper and John (1988), who consider a special class of symmetric normal form games with $I$ agents. Each agent $i$ has to choose an effort level $e_{i} \in[0, E]$. Given effort levels $e_{-i}$ chosen by the opponents of player $i$, a payoff of $\sigma\left(e_{i}, e_{-i}\right)$ results for player $i$. Typical assumptions are that payoffs increase when all effort levels are increased 
simultaneously, and that the marginal payoff of increasing one's effort level diminishes in effort.

Since the normal form games considered are symmetric, it is useful to introduce the notation $V\left(e_{i}, \bar{e}\right)$ for the payoff to agent $i$ when he chooses effort level $e_{i}$, whereas all others take action $\bar{e}$. The utility maximizing effort level for agent $i$, when all other agents choose effort level $\bar{e}$, is denoted by $e_{i}^{*}(\bar{e})$.

The model is analyzed by considering its symmetric Nash equilibria. Although there might in general be Nash equilibria with different agents providing different effort levels, the imposition of an anonymity requirement implies a restriction to symmetric Nash equilibria. It is easily verified that effort levels chosen in a symmetric Nash equilibrium belong to the set $S$ given by

$$
S=\left\{e \in[0, E] \mid V_{1}(e, e)=0\right\},
$$

where $V_{1}$ is the partial derivative of $V$ with respect to its first argument.

An obvious question to ask is under what conditions the effort levels chosen in the model are Pareto optimal. The symmetric Pareto optimal effort levels are found by maximizing $V(e, e)$ over $e$. The effort levels which satisfy the necessary first order conditions are given by

$$
\widetilde{S}=\left\{e \in[0, E] \mid V_{1}(e, e)+V_{2}(e, e)=0\right\},
$$

where $V_{2}$ is the partial derivative of $V$ with respect to its second argument.

The effort levels chosen are inefficient whenever $V_{2}(e, e) \neq 0$. In plain economic terms, the condition that $V_{2}(e, e)$ be zero is called the absence of externalities. Both positive and negative externalities lead to suboptimal effort levels, with positive externalities leading to too high effort levels and negative externalities to too low effort levels. Since it seems plausible that higher effort levels by others increase the value of $V$, it is natural to assume positive externalities. As a consequence, effort levels chosen in a decentralized economy are lower than first best effort levels.

It is here that a first weakness of the model is exhibited. Higher effort levels by other agents do not imply higher values of $V$ in an economic analysis that is carried out in the traditional way. Higher effort levels lead to higher output, which, at a given price per unit, implies higher revenues for the agent that made the effort. Externalities caused by the effort levels chosen by others are absent as soon as trade in commodities is guided by prices. When prices are around to coordinate economic decisions, the underinvestment in effort may well disappear.

Under what conditions may coordination failures arise? To answer that question, it is analyzed first under what conditions multiple equilibria may arise. Since an effort level $\bar{e}$ that corresponds to a symmetric Nash equilibrium satisfies $\bar{e}=e_{i}^{*}(\bar{e})$, multiple equilibria can only exist if the best response function $e_{i}^{*}$ is upward sloping. The best response function is characterized by 
solutions to $V_{1}\left(e_{i}, \bar{e}\right)=0$. By an application of the implicit function theorem, it follows that the slope of $e_{i}^{*}$ at $\bar{e}$ equals $-V_{12}\left(e_{i}^{*}(\bar{e}), \bar{e}\right) / V_{11}\left(e_{i}^{*}(\bar{e}), \bar{e}\right)$.

Under the standard assumption that $V$ is concave, i.e. the marginal benefits from effort are decreasing, we find that $V_{12}>0$ is a necessary condition for the existence of multiple equilibria. The latter condition is well-known in economics, and is called the case of strategic complementarities in Bulow, Geanakoplos and Klemperer (1985). It states that an increase in the effort level of others increases the marginal benefits of an increase in the individual's effort level.

If there are multiple equilibria, and positive externalities, then multiple equilibria give rise to coordination failures. Evaluating the utility of an agent along the best response function yields

$$
\begin{aligned}
\frac{d V\left(e_{i}^{*}(\bar{e}), \bar{e}\right)}{d \bar{e}} & =V_{1}\left(e_{i}^{*}(\bar{e}), \bar{e}\right) \frac{d e_{i}^{*}(\bar{e})}{d \bar{e}}+V_{2}\left(e_{i}^{*}(\bar{e}), \bar{e}\right) \\
& =V_{2}\left(e_{i}^{*}(\bar{e}), \bar{e}\right)>0,
\end{aligned}
$$

where the second equality follows from the fact that $e_{i}^{*}$ is characterized by the condition $V_{1}\left(e_{i}^{*}(\bar{e}), \bar{e}\right)=0$. It follows that the symmetric Nash equilibria are Pareto ranked by the equilibrium action. Moreover, higher action equilibria are preferred to lower action equilibria.

\section{Strategic Models of Coordination Failures with a Coordinating Role for Prices}

Coordination failures may result when there are strategic complementaries and positive externalities. The latter is a natural assumption in an abstract model as in Section 3, but less so when trade takes place on markets and is guided by prices. It is of crucial importance to give more economic flesh to the skeleton set up in the previous section. To achieve this goal, one needs a closed and complete economic model with a role for prices and wages to coordinate economic activity.

In a model with an explicit role for prices, it is possible to analyze a number of interesting issues. It would be possible to study whether involuntary unemployment may occur, where involuntary unemployment is said to exist if there are workers who are unable to sell as much of their labor as they desire at the given wage, or to study whether unemployment is possible with competitive prices.

Roberts (1987) presents a model that meets our criteria. It is the simplest model of a closed economy that allows for coordination failures in a strategic setting. There are five commodities, $X, Y, R, S$, and $M$, four types of agents, $A, B, J$, and $K$, and $n \geq 2$ agents of each type. The commodities $X$ and $Y$ are outputs, $R$ and $S$ are inputs, and $M$ is a commodity that serves as a store of value. Agents of type $A$ and $B$ are producers, and agents of type $J$ and $K$ are workers. 
Producers of type $A$ and $B$ have endowments $\mu_{A}$ and $\mu_{B}$ of commodity $M$. This is the only commodity that enters their utility functions. Producer $A$ has the knowledge to transform input $R$ into output $X$. Producer $B$ knows how to transform input $S$ into output $Y$. Production takes place by means of a constant returns to scale technology; one unit of input yields one unit of output.

A worker of type $J$ has an endowment $\left(\rho, \mu_{J}\right)$ of $R, M$, and a worker of type $K$ has an endowment $\left(\sigma, \mu_{K}\right)$ of $S, M$. Worker $J$ derives utility from consumption of $Y, R$, and $M$, and worker $K$ from $X, S$, and $M$. Notice that no pair of agents has a mutually advantageous trade. Producer $A$ needs inputs from worker $J$, but sells his output to worker $K$. Producer $B$ needs inputs from worker $K$, but sells his output to worker $J$.

The separation of a firm's customers and workers models consumers that specialize in supplying labor, but generalize in consuming outputs. Not only is this a characteristic of the way most economic activity takes place. It also limits strategic effects. A firm cannot increase the demand for its output by raising its wages, and the supply of inputs to a firm does not directly depend on its price and output levels.

The model consists of three stages. In the first stage each firm states a price for its output and a wage for its input. Next each worker announces the amount of input they want to sell to each firm and of output they want to buy. Finally, each firm decides how much of these offers and orders to accept. Since there are $n$ agents of each type, the first stage results in an $n$-tuple of prices and wages for output $X$ and input $R$ and an $n$-tuple of prices and wages for output $Y$ and input $S$. When announcing the amount of inputs to be sold to each firm, workers are required to take into account the feasibility constraint that they cannot sell more inputs than they initially own. When accepting orders and offers, firms are subject to the technological constraints that the total of accepted output orders cannot exceed the total of accepted input offers.

The model described above specifies explicitly how all prices and quantities result from individual choices. It also leads to consistent modeling of out-of-equilibrium behavior. Any sequence of actions, rational or not, leads to clearly defined and feasible outcomes. The typical way to analyze this model is by determining its subgame perfect Nash equilibria. In a subgame perfect Nash equilibrium, each agent correctly forecasts the strategies the others are using and these strategies are best responses to each other at every decision point, including those that would not be reached if behavior actually is generated by the specified strategies.

The model can also be seen as a special case of a general equilibrium model, and can be analyzed by means of its Walrasian solutions. A Walrasian solution is a price-wage vector and an allocation that satisfies a number of conditions. Prices and wages should be identical for all agents of the same type. Given prices and wages, workers maximize their utility subject to their 
budget constraint and the condition that the most they can supply of the input is their initial endowment. Producers maximize profits, that is consumption of good $M$, subject to the available technology. Finally, prices and wages should be such that all markets clear.

Roberts (1987) shows that, given any Walrasian solution, there is a subgame perfect Nash equilibrium such that all firms announce the Walrasian prices and wages, and the resulting allocation is the Walrasian one. To be more precise, the prices and wages specified by all producers in the first stage equal Walrasian prices and wages. Because of the constant returns to scale technologies, this implies that the price of output $X$ is less than or equal to the wage for input $R$, and the price of output $Y$ is less than or equal to the wage for input $S$, with equality holding if there is a positive production level of an output. The total input supplied by a worker in the second stage and the total output delivered by a producer in the third stage, following the quote of Walrasian prices in the first stage, should be equal to the Walrasian amounts. This still allows for many possible equilibrium strategies, since the Walrasian solution does not specify who delivers to whom. Any equilibrium strategy that is consistent with the total amounts specified by the Walrasian solution will do.

A subgame perfect Nash equilibrium should also specify the behavior off the equilibrium path. If, given Walrasian prices and wages, consumer choices differ from Walrasian ones, then let firms maximize profits given the actual orders and offers. No firm gains by cutting its price while raising its wage. If any firm deviates from the Walrasian price and wage in a different way, then specify all orders to and offers from it as zero. Workers dealing with the deviating firm go to other firms and have their Walrasian orders and offers filled. Notice that if all workers act in this way, then this kind of behavior is optimal, even when a deviating firm has raised both its price and wage or lowered both. At any price-wage vector at which more than one firm is deviating from the Walrasian levels, specify any subgame equilibrium, for instance one with all orders and offers being zero. It can be verified that the strategies specified above constitute a subgame perfect Nash equilibrium that leads to the Walrasian outcome.

The Walrasian outcome is not the only one that can be sustained as a subgame perfect Nash equilibrium. Consider some Walrasian solution, and any integer $k, 0 \leq k \leq n$. There exists an equilibrium in which all firms announce the Walrasian prices and wages, and in the equilibrium $k$ of the consumers of each type get their Walrasian allocations and the $n-k$ remaining consumers of each type receive their initial endowments, buying and selling zero amounts. The arguments needed to show this result are similar to the ones used in the previous paragraph. Note in particular that an inactive firm sees no demand for the output that hiring a worker yields, and will therefore decide not to hire such a worker in the first place. This phenomenon is caused by the strict separation of workers and consumers. 
There exist at least $n$ equilibria in the model, most of which are characterized by inefficiently low levels of output and involuntary unemployment, everything at Walrasian prices. Since the framework used is rather specific, it is important to consider how robust these results are to the exact specification of the game.

Jones and Manuelli (1992) consider a slightly different game. Up to now it is assumed that goods are produced on a "made-to-order" basis. A precommitment on the part of the buyers is needed before any production can take place. Jones and Manuelli (1992) consider the case where goods are manufactured for inventory. They assume exactly the same primitives as before (five goods, four types of agents, utility functions, endowments and technology), but a slightly different institutional set-up.

Suppose now that the second stage is disentangled into two stages, separating the announcement of input offers and the placement of output orders. The latter is now supposed to occur at the very end. The complete institutional set-up of the game is therefore as follows. In the first stage firms set wages and prices. In the second stage workers announce the amount of input they want to sell. In the third stage firms decide how much of these offers to accept, and production takes place. In the fourth stage workers announce how much output they want to buy.

Production on a made-to-order basis and production for inventory lead to quite distinct conclusions. In particular, it is not difficult to show that the no-trade equilibrium is no longer an equilibrium in the latter specification, unless the endowments are already Pareto optimal. Suppose, on the contrary, that the no-trade equilibrium can be sustained as a subgame perfect Nash equilibrium. Then, at the beginning of the fourth stage, workers have supplied none of their inputs. They will express a demand for output, to be paid out of their holdings of commodity $M$. As a consequence, firms facing some demand for sure in the fourth stage are willing to hire labor in the third stage, and workers are willing to offer labor in the second stage. The no-trade solution cannot be sustained as a subgame perfect equilibrium.

Jones and Manuelli (1992) show that for any choice of prices and wages in the first stage, there is a unique pure strategy equilibrium continuation of the game. The vast multiplicity of equilibria obtained in the made-to-order model is therefore ruled out. For separable utility functions, it can also be shown that workers are neither rationed in the labor market, nor in the goods market. The intuition is that a producer would otherwise either lower its wage or increase its price. In particular, there is no involuntary unemployment in this case. 


\section{General Equilibrium Models of Coordination Failures}

Strategic models of coordination failures lead to quite distinct conclusions, dependent on seemingly minor issues in the precise modeling of an economy. Strategic models of coordination failures lack the generality that one would need to be more confident about the importance of their results. It is therefore natural to search for general equilibrium models of coordination failures. Conclusions in a general equilibrium setting tend to be robust to both minor modeling details and the particularities of the economic primitives.

A robust multiplicity of equilibria was shown to occur in the traditional fix-price model in Herings (1996), thereby extending earlier work of van der Laan (1982). Moreover, in Herings (1998) it was shown that the set of equilibria possesses a particular connectedness property. Although the fix-price model seems to explain underutilization of resources as a consequence of trade at "wrong" prices, there is no need to rely on such prices for the multiplicity of equilibria to appear, as was also observed in observed in Citanna, Crès and Villanacci (1997).

The interpretation of the multiplicity of equilibria as coordination failures and the link to the macro-economic literature on coordination failures surveyed in the previous two sections was made by Jacques Drèze, resulting in the papers Drèze (1997) and Herings and Drèze (1998). The exposition in this section is a simplified version of the latter paper. ${ }^{1}$

Consider the classical general equilibrium model with $H$ households and $F$ firms. A firm $f$ is described by its production possibility set $Y^{f}$. A household $h$ is characterized by its consumption set $X^{h}$, utility function $u^{h}$, initial endowment $e^{h}$, and shares $\theta^{f h}$ in the profits of firm $f$. Suppose that trade takes place against Walrasian prices $p^{*}$, so unconstrained total supply equals unconstrained total demand at prices $p^{*}$.

A deviation from the standard framework occurs by assuming that it is not common knowledge that the prices are Walrasian. Even when all agents know that prices are Walrasian, it is not necessarily the case that all agents know that all other agents know that prices are Walrasian, and it is even less likely that all agents know that all other agents know that all other agents know that prices are Walrasian, and so on. Common knowledge that prices are Walrasian requires structural knowledge about the economy, very much at odds with the standard general equilibrium paradigm that in a decentralized economy agents only have to maximize utility given the prices that are quoted in the market place.

When it is not common knowledge that prices are Walrasian, it no longer makes sense for agents to express their unconstrained demands and supplies. In particular, they should form expectations on supply and demand possi-

\footnotetext{
${ }^{1}$ A merger of that paper with Citanna, Crès and Villanacci (1997) resulted in the one of Citanna, Crès, Drèze, Herings and Villanacci (2001).
} 
bilities of all commodities. One particular instance of such expectations are the very optimistic expectations that supply and demand possibilities always exceed supply and demand desirabilities. If all agents hold such optimistic expectations, they will find out that their expectations are justified, and they will consume the Walrasian allocation.

There can be other expectations apart from the very optimistic ones. The intriguing question is whether such expectations can be self-confirming. An underemployment equilibrium of the economy consists of expectations on supply possibilities that are self-confirming. ${ }^{2}$ Those expectations are said to be self-confirming if the utility maximizing demand of households given these expectations equals the profit maximizing supply of firms given these expectations, all optimization taking place at Walrasian prices.

The set of underemployment equilibria is reduced further by imposing an additional rationality constraint on the expectations. It makes sense to model explicitly that in case of excess supply, there is some rationing system that specifies how much each agent may supply. The simplest case of such a rationing system is the uniform rationing system, where for each commodity there is a maximal amount to be supplied that is common to all agents. The set of underemployment equilibria is reduced by requiring that the expectations of the agents are compatible with the prevailing rationing system.

It is straightforward that apart from the very optimistic Walrasian expectations, there is also an equilibrium with very pessimistic no-trade expectations. When all agents expect that no supply of any commodity is possible such expectations become self-confirming. Firms maximize profits by remaining inactive. Indeed, they expect no demand for their output, and avoid any cost of production. As a consequence, households have no way to earn income, resulting in the absence of any purchasing power, and the consumption of their initial endowments. Total constrained demand matches total constrained supply and is equal to zero for all commodities.

There are many more underemployment equilibria. The formal result states that there is a connected set of underemployment equilibria that ranges from a no-trade equilibrium to an underemployment equilibrium with very optimistic expectations in at least one market. Examples show that the latter equilibrium may or may not be the Walrasian equilibrium. Typically, the set of underemployment equilibria is a one-dimensional continuum. Intuitively, this can be explained as follows. There are as many instruments, in this case expectations levels, to achieve market clearing as there are commodities. But by virtue of Walras' law there is no need to clear the last market when all but one markets are in equilibrium. One degree of freedom is left over, leading to the one-dimensional continuum. There are not only multiple equilibria, but also coordination failures as the Walrasian equilibrium is typically strictly

\footnotetext{
${ }^{2}$ Because of the interest to analyze unemployment, the focus is here on expectations on supply possibilities. The extension to expectations on demand possibilities is straightforward.
} 
Pareto superior to the no-trade equilibrium, or any underemployment equilibrium in the neighborhood of a no-trade equilibrium.

A highly stylized example with one production sector and one representative household can be used to illustrate the result mentioned above. The production sector produces output from labor. The representative household consumes output and supplies labor. The production sector and the household have to form expectations about the maximal supply of output and the maximal supply of labor possible. If the production sector expects that the total demand for output is low, they will hire only a limited amount of labor. This has a negative impact on the income of the representative household, and thereby leads to a low demand for outputs, exactly confirming the expectations of the production sector. The result implies that infinitely many expectation levels, varying from very pessimistic to very optimistic, are consistent with equilibrium.

The result makes clear that the observation of excess supply is not sufficient to infer the existence of price and wage distortions. Downwards pressure on prices or wages is not very helpful to get out of this situation. When prices or wages are not at Walrasian values, similar coordination failures exist, and will even be compounded by the traditional consequences of "wrong" prices. Pareto improvements can only be made by a simultaneous recoordination of expectations of all agents, by no means an easy task to accomplish.

\section{Conclusion}

The paper exhibits coordination failures as an interesting source of unemployment, which complements the traditional neo-classical and Keynesian views. Economic models with coordination failures can be classified in three categories; two types of game-theoretic models and one class of general equilibrium models. In all cases, coordination failures arise as a consequence of self-confirming pessimistic expectations.

An issue not touched upon in Section 5 is the distinction between nominal prices and real prices. Section 5 formulates the model in real terms. The nominal specification is probably more desirable, since in reality commodities are not exchanged against commodities, but against money. A model in nominal terms necessitates an explicit modeling of money demand and supply. Although there seem to be no major obstacles to extend the model by a monetary sector as in Drèze and Polemarchakis (1999), it remains to be verified that its structural properties will not change.

For very simple game-theoretic models, theories of equilibrium selection exist. These theories amount to theories of expectation formation in the setting with coordination failures. The available theories of expectation formation make clear that there is no reason that coordination on the Pareto dominant equilibrium takes place. Considerations related to risk dominance turn out to be of crucial importance. The extension of the ideas of equilib- 
rium selection in game theory to equilibrium selection in general equilibrium theory seems a natural next step to take.

A particular problem for equilibrium selection in general equilibrium theory is that this theory has not made much progress in modeling out of equilibrium behavior. With infinitely many equilibria around to coordinate on, coordination on one equilibrium seems a task too heroic to impose on agents. A model with a full-fledged dynamic specification of expectation formation, in a general equilibrium setting, and including the specification of trading processes out of equilibrium, remains highly desirable.

\section{References}

1. Aumann, R.J. (1990), "Nash Equilibria Are Not Self-Enforcing," in J.J. Gabszewicz, J.F. Richard, and L.A. Wolsey (eds.), Economic Decision-Making: Games, Econometrics, and Optimization, 201-206.

2. Bénassy, J.-P. (1975), "Neo-Keynesian Disequilibrium Theory in a Monetary Economy," Review of Economic Studies, 42, 503-523.

3. Blad, M.C. (1978), "On the Speed of Adjustment in the Classical Tatonnement Process: A Limit Result," Journal of Economic Theory, 19, 186-191

4. Bryant, J. (1983), "A Simple Rational Expectations Keynes-Type Model," Quarterly Journal of Economics, 98, 525-528.

5. Bulow, J., J. Geanakoplos, and P. Klemperer (1985), "Multimarket Oligopoly: Strategic Substitutes and Complements," Journal of Political Economy, 93, 488511.

6. Carlsson, H., and E. van Damme (1993), "Global Games and Equilibrium Selection," Econometrica, 61, 989-1018.

7. Citanna, A., H. Crès, J.H. Drèze, P.J.J. Herings, and A. Villanacci (2001), "Continue of Underemployment Equilibria Reflecting Coordination Failures, Also at Walrasian Prices," forthcoming in Journal of Mathematical Economics.

8. Citanna, A., H. Crès, and A. Villanacci (1997), Underemployment of Resources and Self-confirming Beliefs : Nonwalrasian Allocations at Walrasian Prices, Working Paper, pp. 1-31.

9. Cooper, R., and A. John (1988), "Coordinating Coordination Failures in Keynesian Models," Quarterly Journal of Economics, 103, 441-463.

10. Drèze, J.H. (1975), "Existence of an Exchange Equilibrium under Price Rigidities," International Economic Review, 16, 301-320.

11. Drèze, J.H. (1997), Walras-Keynes Equilibria-Coordination and Macroeconomics, European Economic Review, 41, 1735-1762.

12. Drèze, J.H. (2001), "On the Macroeconomics of Uncertainty and Incomplete Markets," Recherches Economiques de Louvain, 67, 5-30.

13. Drèze, J.H., and C. Gollier (1993), "Risk Sharing on the Labour Market," European Economic Review, 37, 1457-1482.

14. Drèze, J.H., and H.M. Polemarchakis (1999), "Money and Monetary Policy in General Equilibrium," in A.P. Kirman and L.A. Gérard-Varet (eds.), Economics Beyond the Millennium, Oxford University Press, Oxford, pp. 55-77.

15. Ellison, G. (1993), "Learning, Local Interaction, and Coordination," Econometrica, 61, 1047-1071. 
16. Friedman, M. (1968), "The Role of Monetary Policy," American Economic Review, 58, 1-17.

17. Grandmont, J.-M. (1977), "Temporary General Equilibrium Theory," Econometrica, 45, 535-572.

18. Harsanyi, J.C., and R. Selten (1988), A General Theory of Equilibrium Selection in Games, MIT Press, Cambridge.

19. Herings, P.J.J. (1996), "Equilibrium Existence Results for Economies with Price Rigidities," Economic Theory, 7, 63-80.

20. Herings, P.J.J. (1997), "Endogenously Determined Price Rigidities," Economic Theory, 9, 471-498.

21. Herings, P.J.J. (1998), "On the Existence of a Continuum of Constrained Equilibria," Journal of Mathematical Economics, 30, 257-273.

22. Herings, P.J.J., and J.H. Drèze (1998), "Continua of Underemployment Equilibria," CentER Discussion Paper 9805, CentER, Tilburg University, Tilburg, pp. 1-32.

23. Herings, P.J.J., A. Mauleon, and V. Vannetelbosch (2001), "Fuzzy Play, Matching Devices and Coordination Failures," METEOR Research Memorandum 01/00, Universiteit Maastricht, pp. 1-11.

24. Jones, L.E., and R.E. Manuelli (1992), "The Coordination Problem and Equilibrium Theories of Recessions," American Economic Review, 82, 451-471.

25. Kalai, E., and D. Samet (1985), "Unanimity Games and Pareto Optimality," International Journal of Game Theory, 14, 41-50.

26. Kandori, M., G. Mailath, and R. Rob (1993), "Learning, Mutation and Long Run Equilibria in Games," Econometrica, 61, 29-56.

27. Laan, G. van der (1982), "Simplicial Approximation of Unemployment Equilibria," Journal of Mathematical Economics, 9, 83-97.

28. Roberts, J. (1987), "An Equilibrium Model with Involuntary Unemployment at Flexible, Competitive Prices and Wages," American Economic Review, r7, 856-874.

29. Tuinstra, J. (2000), "The Emergence of Political Business Cycles in a Twosector General Equilibrium Model," European Journal of Political Economy, 16, 509-534.

30. Weddepohl, C. (1997), "Simulating Tatonnement in a Production Economy," Economic Theory, 10, 551-558.

31. Younès, Y. (1975), "On the Role of Money in the Process of Exchange and the Existence of a Non-Walrasian Equilibrium," Review of Economic Studies, 42, 489-501.

32. Young, H.P. (1993), "The Evolution of Conventions," Econometrica, 61, 57-84. 